\title{
Characteristics and Predictors of Early and Delayed Responders to Ranibizumab Treatment in Neovascular Age-Related Macular Degeneration: A Retrospective Analysis from the ANCHOR, MARINA, HARBOR, and CATT Trials
}

\author{
Richard Gale $^{\mathrm{a}}$ Jean-Francois Korobelnik ${ }^{\mathrm{b}-\mathrm{d}}$ Yit Yang ${ }^{\mathrm{e}}$ Tien Y. Wong ${ }^{\mathrm{f}, \mathrm{g}}$ \\ a York Hospital, York, UK; ${ }^{b}$ Service d'ophtalmologie, CHU de Bordeaux, ' ISPED, University of Bordeaux, and \\ ${ }^{d}$ Inserm, U1219 - Bordeaux Population Health Research Center, Bordeaux, France; e Eye Infirmary, \\ Royal Wolverhampton Hospitals NHS Trust, Wolverhampton, UK; ${ }^{f}$ Singapore Eye Research Institute, Singapore \\ National Eye Centre, and ${ }^{9}$ Duke-NUS Medical School, National University of Singapore, Singapore
}

\section{Keywords}

Anti-vascular endothelial growth factor $\cdot$ Age-related macular degeneration - Macular degeneration

\begin{abstract}
Purpose: This retrospective review examined visual acuity (VA) in subjects with neovascular age-related macular degeneration and identified early and delayed response to ranibizumab. Procedures: MARINA, ANCHOR, HARBOR, and CATT published data were examined for response with monthly versus individualized dosing and predictors of early versus delayed response. Results: Data were available for 1,631 subjects; $18-29 \%$ were early gainers and $15-16 \%$ were delayed gainers. Of the early gainers, $72-83 \%$ maintained their bestcorrected VA gain at month 12 with monthly or individualized dosing. Delayed gainers in HARBOR almost reached the same level of response as early gainers by 12 months who were able to maintain their response. The main predictor of response was baseline VA. Conclusion: There are two distinct types of ranibizumab response; some responded by month 3 , while others took up to 12 months. In delayed responders, this may have implications for switching or not switching therapies.
\end{abstract}

(c) 2016 The Author(s)

Published by S. Karger AG, Basel

\section{KARGER}

E-Mail karger@karger.com www.karger.com/oph

\section{(C) 2016 The Author(s)}

Published by S. Karger AG, Basel
Karger

Open access

This article is licensed under the Creative Commons AttributionNonCommercial-NoDerivatives 4.0 International License (CC BYNC-ND) (http://www.karger.com/Services/OpenAccessLicense). Usage and distribution for commercial purposes as well as any distribution of modified material requires written permission.

\section{Introduction}

Age-related macular degeneration (AMD) affects more than 100 million people globally [1] and is the leading cause of irreversible vision loss among people over 50 years of age in developed countries [2, 3]. "Wet" or neovascular AMD (nAMD) results in significant vision deterioration from choroidal neovascularization into the neural retina and the development of fibrous scars due to leaking fluid, lipids, and blood [4]. Considerable advances in treatment have been made during the last 20 years as the pathophysiologic mechanisms and targets in the disease process have been identified [4]. One such molecule is vascular endothelial growth factor (VEGF), and anti-VEGF therapy has become the standard of care for subjects with nAMD based on the findings of the ranibizumab ANCHOR and MARINA studies [5, 6]. These pivotal clinical trials demonstrated that, when given monthly, anti-VEGF therapy was associated with significant improvements in visual acuity (VA) and prevented loss of vision or maintained vision in the majority of subjects. Comparable visual outcomes have also been seen with an individualized ranibizumab dosing regimen in other trials [7-9]. 
However, it is now clear that the response to antiVEGF treatment is heterogeneous. For ranibizumab, one trial showed that only $6 \%$ of subjects typically require monthly dosing, while the remainder can be treated less frequently using an individualized approach [10]. Thus, real-life treatment of nAMD is typically individualized for most subjects following initial monthly treatment [11-13], with clear benefits seen with early treatment [14]. Indeed, individualized dosing is recommended in the prescribing information for ranibizumab and the intervals between doses can be extended according to the treating physician's opinion and an assessment of disease severity [11]. The management of patients using an individualized approach, however, is made more complex by the difficulty in determining whether an optimal treatment response has been achieved. This is important as such an assessment may inform the decision to switch to other treatments, such as an alternative anti-VEGF agent, to add in photodynamic therapy, or to continue with the anti-VEGF treatment [15]. Opinions on the time point at which an adequate response should be determined also differ among clinicians, with some recommending this is assessed at 3 months [15], while others prefer to continue treatment as planned for 12 months $[5,6]$ as some subjects may not respond quickly to treatment. Likewise, the definition of a good response is open to debate, but a $\geq 15$-letter gain is an accepted standard [15]. The concept of early and delayed responses has been investigated in a retrospective analysis by Hariprasad et al. [16]. In this analysis, VA data from subjects with nAMD who were treated with fixed monthly doses of ranibizumab in MARINA [5] and ANCHOR [6] were pooled and compared with pooled data from PIER [17] and SAILOR [18], where subjects received less frequent administration of ranibizumab after the initial loading doses. This analysis of data from 1,824 ranibizumab-treated subjects indicated 14.9$29.4 \%$ of subjects had a $\geq 15$-letter gain from baseline at month 3 (early responders) across the four studies [16]. Indeed, 14.7 and $16.1 \%$ of subjects who continued to receive fixed monthly dosing in ANCHOR and MARINA had a delayed response ( $\geq 15$-letter gain from baseline at month 12). In comparison, a delayed response was seen in 5.0\% who received quarterly dosing in PIER [17] and $6.0 \%$ who received criteria-based PRN dosing in SAILOR [18]. This finding raises concerns over whether individuals are prematurely labelled as 'non- or suboptimal responders' and are thus switched to a different therapy when in fact the subject may have a delayed response, something that has been seen recently in HARBOR [19]. Indeed, over $75 \%$ of subjects are usually treated with be- tween 3 and 6 injections of an anti-VEGF agent prior to switching because of a suboptimal response and it may be that some of these are switched unnecessarily [20].

A limitation of the previous review by Hariprasad et al. [16] was that data from SAILOR and PIER studies were included, but SAILOR and PIER utilized variable quarterly/PRN dosing strategies that are now not used routinely in current clinical practice and which have been associated with less favorable outcomes compared with the fixed monthly dosing schedules utilized in MARINA and ANCHOR. In addition, data are lacking on how the pattern of response may change with different treatment regimens (e.g., monthly dosing versus an individualized approach). To address these limitations, we conducted this review using data from HARBOR $[7,10]$ and CATT $[8,9]$, as well as from MARINA [5] and ANCHOR [6]. Each of these four randomized controlled trials included subjects who were treated in a similar manner to those seen in clinical practice, with either fixed monthly dosing (MARINA and ANCHOR) or individualized monthly or PRN dosing in HARBOR and CATT that was based on individual response. We also examined the pattern of $\mathrm{VA}$ response (defined as a gain of $\geq 15$ letters) to identify subjects with nAMD who had an early or delayed response to ranibizumab treatment. Early responders were defined as those who gained $\geq 15$ letters from baseline as measured at month 3 and delayed responders defined as subjects who did not gain $\geq 15$ letters from baseline at month 3 , but subsequently gained $\geq 15$ letters from baseline as measured at month 12 [16]. We also identified possible predictors of these different types of response. It was hoped these predictors of response at month 3 could be used to distinguish between subjects who should continue ranibizumab from those subjects who would benefit from switching treatment.

\section{Methods}

Patient Data Set

This retrospective analysis was conducted using data from four large, 2-year, randomized controlled trials (MARINA [5], ANCHOR [6], HARBOR $[7,10]$, and CATT $[8,9])$ of intravitreal ranibizumab treatment in subjects with nAMD. Details of inclusion and exclusion criteria, study design, and data collection information for these trials has previously been published elsewhere [5-10] and are summarized in Table 1 for completeness.

Statistical Analysis

Data were analyzed at month 3 to identify those subjects who achieved early VA gains with treatment, and at month 12 to identify those with a delayed response who achieved VA gains between 
Table 1. Overview of MARINA, ANCHOR, HARBOR, and CATT

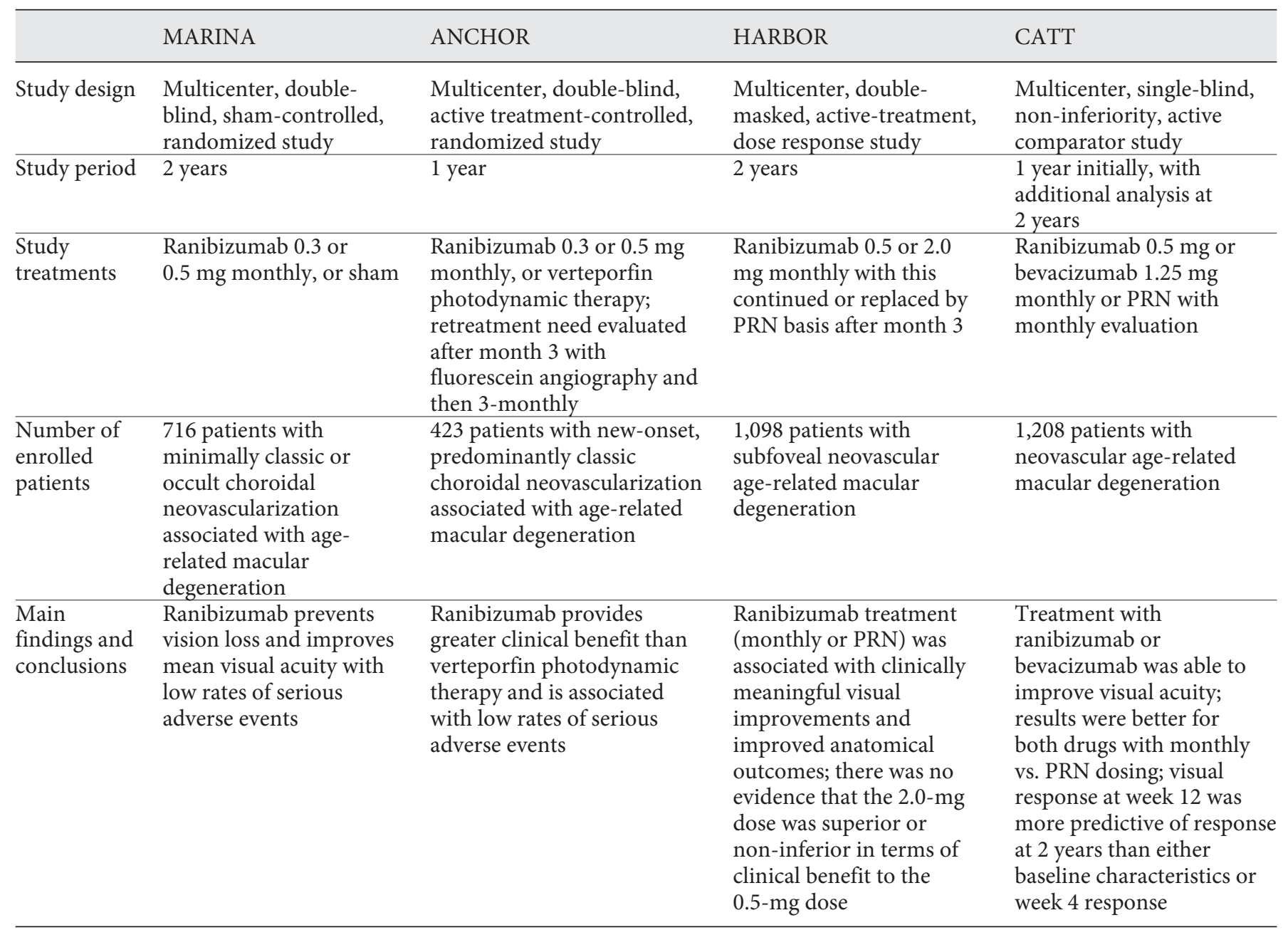

months 4 and 12. As such, for each trial, subjects who achieved a $\geq 15$-letter gain were categorized based on best corrected VA (BCVA) change from baseline over time as either early $\geq 15$-letter gainers (i.e., gained $\geq 15$ letters from baseline at month 3 ) or delayed $\geq 15$-letter gainers (i.e., did not gain $\geq 15$ letters from baseline at month 3 , but did gain $\geq 15$ letters at month 12 ).

BCVA data, as assessed by the Early Treatment Diabetic Retinopathy Study (ETDRS) visual acuity chart, were analyzed in subjects treated for 12 months with monthly ranibizumab $0.3 / 0.5 \mathrm{mg}$ (pooled group) in ANCHOR $(n=279)$ and MARINA $(n=478)$, or with monthly as well as individualized dosing of ranibizumab 0.5 mg in HARBOR $(n=275$ each) and CATT $(n=301$ in monthly, $n=298$ in PRN). Using these data, the percentage of early and delayed $\geq 15$-letter gainers were determined and then compared between the monthly and PRN dosing groups.

Where available, data on baseline characteristics such as age, sex, VA gains, previous AMD therapy, lesion type, and anatomy were also compared between early 15-letter gainers and delayed 15-letter gainers to identify potential baseline predictors of response.

Early and Delayed Response to

Ranibizumab in Neovascular AMD

\section{Results}

Data were available for 1,631 subjects treated with a monthly ranibizumab regimen in ANCHOR [6] and MARINA [5] and monthly as well as individualized dosing of ranibizumab in HARBOR [7] and CATT [9].

\section{Early and Delayed Responders (12-Month Data)}

Subjects treated with monthly ranibizumab who were classified as early $\geq 15$-letter gainers accounted for between 18 and $29 \%$ of subjects (29\% in ANCHOR, $18 \%$ in MARINA, $24 \%$ in HARBOR, and $18 \%$ in CATT) as shown in Figure 1, while 15-16\% were considered as delayed $\geq 15$-letter gainers (15\% in ANCHOR and $16 \%$ in each of MARINA, HARBOR, and CATT). In addition, data from Figure 2 show $13 \%$ of subjects in HARBOR and 


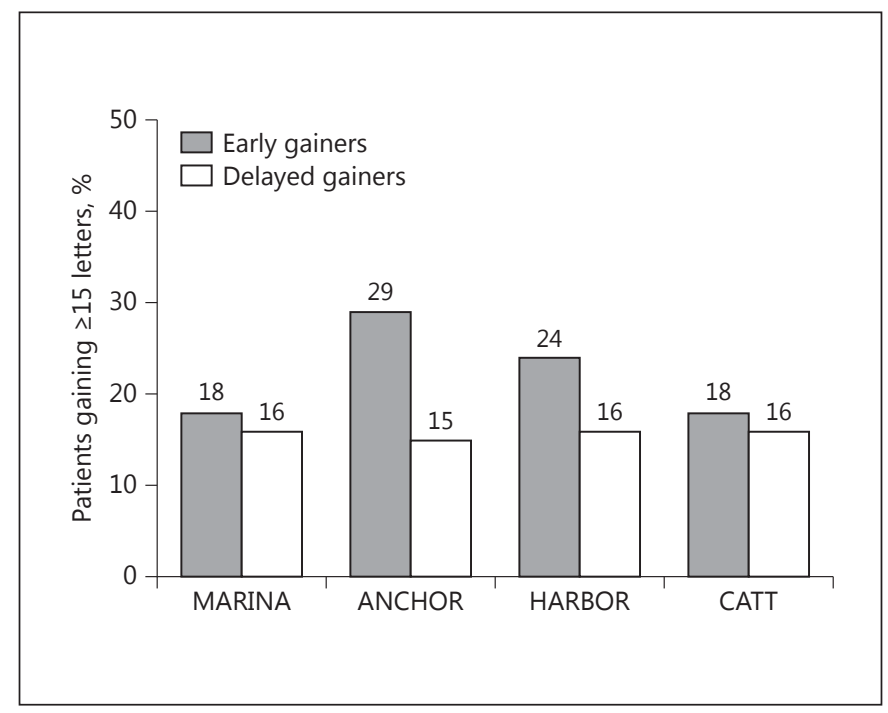

Fig. 1. Proportion of subjects with early and delayed $\geq 15$-letter gain with monthly ranibizumab dosing across the neovascular agerelated macular degeneration trials.

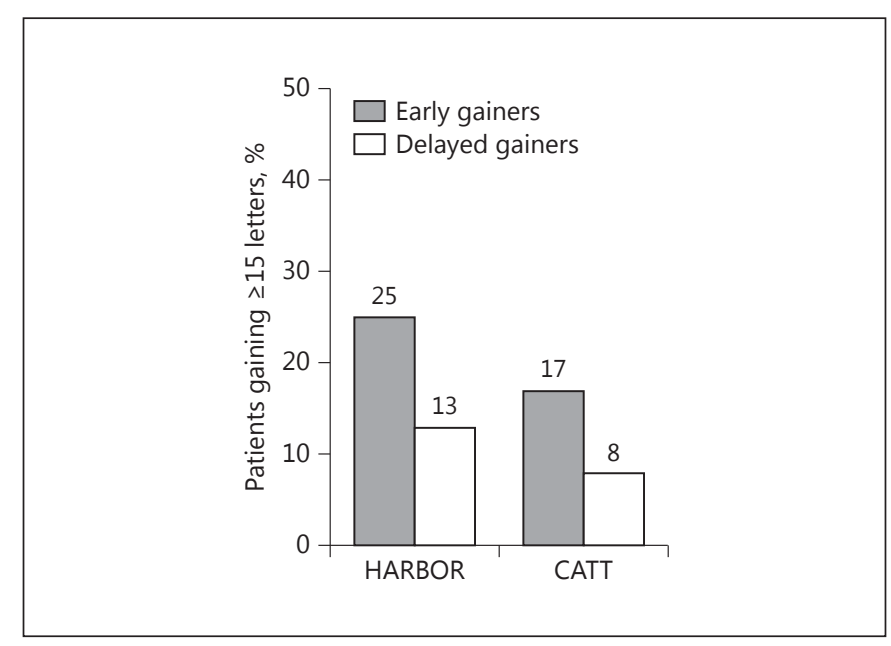

Fig. 2. Proportion of subjects with early and delayed $\geq 15$-letter gain with ranibizumab PRN dosing regimen.

$8 \%$ in CATT had a delayed response but despite this were able to achieve a BCVA improvement at month 12 with individualized ranibizumab dosing.

With monthly dosing, $72-83 \%$ of the early gainers from ANCHOR, MARINA, and HARBOR were able to maintain their $\geq 15$-letter BCVA gain at month 12 (e.g., $79,72,83$, and $76 \%$, respectively; Fig. 3). With individualized dosing, this percentage was similar: $76 \%$ of early

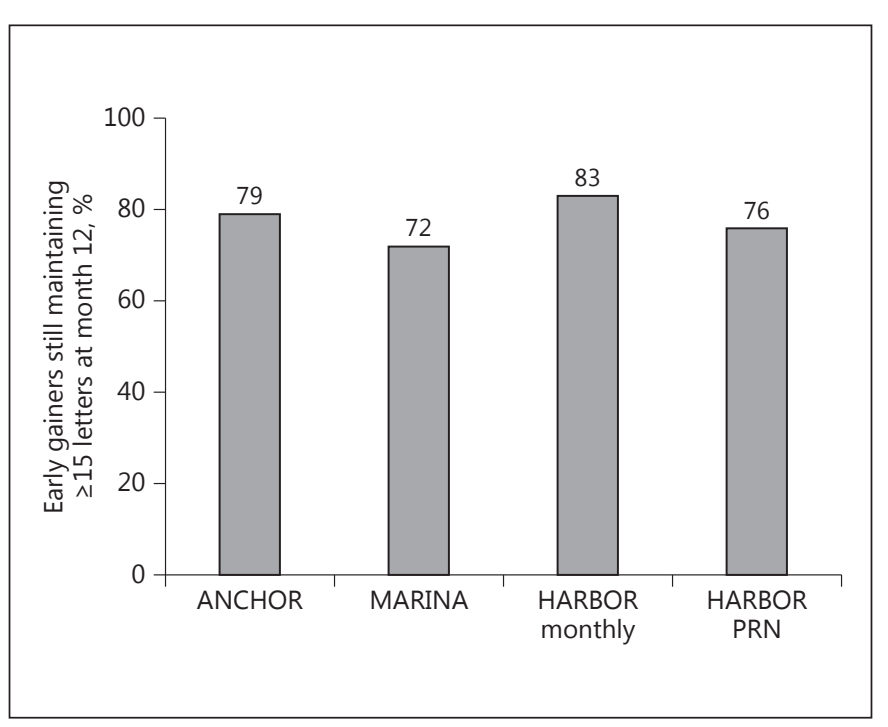

Fig. 3. Proportion of early gainers who were able to maintain a $\geq 15$-letter gain at month 12 with ranibizumab monthly and PRN dosing regimen.

gainers from HARBOR maintained their $\geq 15$-letter BCVA gain at month 12 (comparable data are not available from CATT).

Change in VA gains seen over time in the HARBOR study is presented in Figure 4. Early gainers maintained their gains of a mean of 20 letters up to 12 months and this was only slightly higher than the mean VA achieved in the delayed gainer group. This indicated that by month 12 , the delayed gainers had almost reached the same level of VA response as the early gainers.

\section{Potential Predictors of Response}

As shown in Table 2, subjects categorized as early gainers and who were able to achieve a response of $\geq 15$ letters by month 3 had significantly lower mean VA at baseline compared with delayed gainers in ANCHOR, MARINA (both $p<0.05)$, and HARBOR ( $p=0.0013$ in ranibizum$\mathrm{ab}$ monthly group). There were, however, no significant differences in terms of other baseline characteristics such as lesion characteristics, presence of fibrosis, scarring, or previous administration of intravitreal injections that were able to predicting response. Data from HARBOR suggest differences in the presence of pigment epithelial detachment (PED; $p=0.007$ ) and the presence of blood $(p=0.08)$ are seen between early and delayed responders at baseline, but these factors are comparable between groups by month 3 [19]. Data from CATT were not available to be included in this part of the analysis. 
Fig. 4. Mean best corrected visual acuity (BCVA) change in early and delayed $\geq 15$-letter gain in HARBOR.

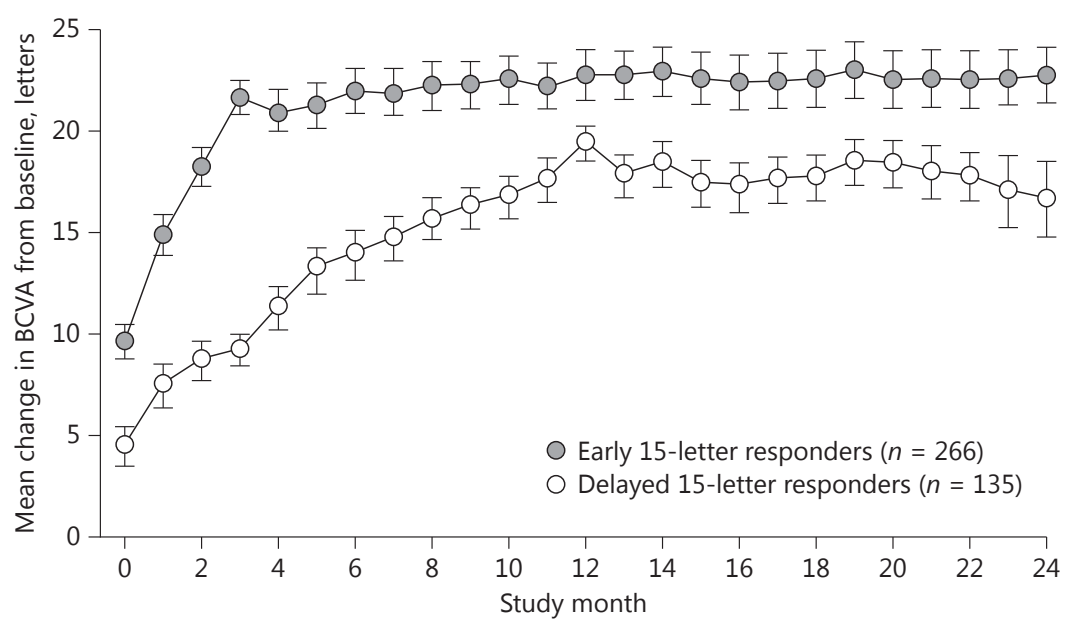

Table 2. Overview of baseline characteristics of early and delayed gainers enrolled in ANCHOR, MARINA, and HARBOR

\begin{tabular}{|c|c|c|c|c|c|c|}
\hline \multirow[t]{2}{*}{ Demographics } & \multicolumn{2}{|c|}{ ANCHOR $[6,12,16]$} & \multicolumn{2}{|c|}{ MARINA $[5,12,16,21]$} & \multicolumn{2}{|c|}{ HARBOR $[7,10,19]$} \\
\hline & $\begin{array}{l}\text { early } \\
\geq 15 \text { letters } \\
(n=82)\end{array}$ & $\begin{array}{l}\text { delayed } \\
\geq 15 \text { letters } \\
(n=41)\end{array}$ & $\begin{array}{l}\text { early } \\
\geq 15 \text { letters } \\
(n=87)\end{array}$ & $\begin{array}{l}\text { delayed } \\
\geq 15 \text { letters } \\
(n=77)\end{array}$ & $\begin{array}{l}\text { early } \\
\geq 15 \text { letters } \\
(n=266)\end{array}$ & $\begin{array}{l}\text { delayed } \\
\geq 15 \text { letters } \\
(n=135)\end{array}$ \\
\hline Gender, \% female & 46 & 54 & 63 & 66 & NA & NA \\
\hline Mean age, years & 76 & 75 & 77 & 76 & 76.9 & 77.6 \\
\hline Mean VA, letters & $43^{\mathrm{a}}$ & 51 & $47^{\mathrm{a}}$ & 53 & $50^{\mathrm{b}}$ & $55^{\mathrm{b}}$ \\
\hline Prior therapy for AMD, $\%$ & 17 & 17 & 9 & 5 & NA & NA \\
\hline Mean central foveal thickness, $\mu \mathrm{m}$ & NA & NA & NA & NA & 375 & 339 \\
\hline Mean total area of lesion, DA & 1.7 & 1.6 & 4.0 & 4.2 & 2.8 & 3.3 \\
\hline Mean CNV, DA & 1.3 & 1.2 & 3.8 & 4.1 & 2.7 & 3.1 \\
\hline Mean classic CNV, DA & 1.1 & 1.1 & 0.2 & 0.2 & NA & NA \\
\hline Classic CNV, \% of lesion area & 65 & 69 & 5 & 4 & NA & NA \\
\hline Leakage + RPE staining & 2.8 & 2.5 & 3.1 & 3.4 & NA & NA \\
\hline Presence of PED & NA & NA & NA & NA & 44.4 & $58.5^{\mathrm{c}}$ \\
\hline Presence of blood & NA & NA & NA & NA & $90.2^{\mathrm{d}, \mathrm{e}}$ & $84.1^{\mathrm{d}, \mathrm{f}}$ \\
\hline
\end{tabular}

AMD, age-related macular degeneration; CNV, choroidal neovascularization; DA, disc area; NA, not available; PED, pigment epithelium detachment; RPE, retinal pigment epithelium; VA, visual acuity. ${ }^{\mathrm{a}} p<0.05 ;{ }^{\mathrm{b}} p<0.001 ;{ }^{\mathrm{c}} p=0.007 ;{ }^{\mathrm{d}} p=0.08 ;{ }^{\mathrm{e}} n=265$; ${ }^{\mathrm{f}} n=132$.

\section{Discussion}

In our retrospective analysis of data from four large randomized, multicenter clinical trials of ranibizumab for the treatment of nAMD, we found that between 18 and $29 \%$ of subjects can be classified as early responders, defined as those who responded early to ranibizumab treatment with $a \geq 15$-letter gain in the first 3 months of treatment, and $15-16 \%$ can be classified as delayed responders, defined as subjects who did not gain $\geq 15$ letters from baseline at month 3 , but subsequently gained $\geq 15$ letters from baseline as measured at month 12 .

With respect to early responders, it is interesting that HARBOR subjects received three injections of ranibizumab on month 1,2, and 3 before beginning a PRN regimen and so early responders in this study effectively re- 
ceived once monthly ranibizumab, something that is commonly seen in PRN studies. This is in contrast to CATT, where a PRN regimen was initiated after the initial ranibizumab injection, and therefore in CATT these early responders may have received fewer than three injections, and hence $18 \%$ in CATT were classified as early $\geq 15$-letter gainers versus $24 \%$ in HARBOR. There was also a subset of subjects who achieved $\geq 15$-letter VA gains between months 4 and 12, which indicates some subjects may have a delayed response to ranibizumab treatment. This delay appears to be irrespective of the treatment regimen, with comparable proportions of subjects classified as early gainers and delayed gainers for monthly and individualized ranibizumab. In addition, while not all subjects respond quickly to ranibizumab treatment, the subjects who were considered delayed gainers were able to achieve almost the same mean improvements in VA as seen in the early gainer group who had rapid gains by month 3 and achieved a mean of 20 letters by month 12 .

Hariprasad et al. [16], who conducted a similar study to ours, also found there were fewer delayed responders when ranibizumab was given quarterly/PRN in PIER [17] and SAILOR [18] than in CATT and HARBOR, although the data from this study was not as reflective as the real-life setting of the data we used in our analysis. This finding therefore might reflect the less stringent retreatment criteria of the earlier trials in the case of SAILOR, and undertreatment in the case of PIER, and highlight the importance of continuing treatment in all subjects including those who have a delayed (or a perceived suboptimal response), as a substantial proportion of subjects who do not achieve a treatment response after 3 months will go on to achieve this if treatment is continued. While the recent ASRS survey shows that the majority of physicians give only 3-6 injections of an anti-VEGF agent before switching if they do not perceive a treatment response, we would argue that the results of this analysis suggest that definitive treatment success should be defined by the outcomes at 12 months rather than 3 months [20]. In addition, there is a perception that the VA seen at 3 months is the best that a particular subject is likely to achieve, but this assumption is likely to be incorrect for some, and those subjects with a delayed response are likely to continue to see their VA rise with continued monthly injections or a PRN regimen. Our study indicates a switch may not be necessary for subjects with a delayed response and these patients could continue to receive ranibizumab. Indeed, those with a perceived suboptimal response may slowly improve their VA and gain letters over time without the need to change treatment. It is therefore important to try and identify predictive factors so that subjects most likely to experience a delayed response can be identified and a potential switch postponed, thereby allowing continuing therapy and the development of a delayed response.

Our review of the literature indicates higher baseline VA may be predictive of a delayed response to ranibizumab treatment, with baseline values of 43-50 letters seen in early gainers versus $51-55$ letters in delayed gainers ( $p<0.05$ for ANCHOR, MARINA, and HARBOR). We feel, as all subjects in these studies had sufficient capacity for a 15-letter improvement at baseline, this difference in response cannot be explained entirely by differences in baseline VA between subjects with an early versus delayed response. In addition, real-world studies have also confirmed the strong correlation between baseline VA and VA outcomes as well as a possible link between baseline PED, the presence of blood, and/or retinal pigment epithelium (RPE) atrophy $[19,21-26]$ to be predictive of response to treatment. Others have also shown increased subretinal tissue and the presence of subretinal fluid $[27,28]$ or epiretinal membrane $[29]$ to be predictive, but this has not been confirmed by some authors [25]. Our analysis indicates the subject's starting VA and the presence of PED and/or blood at baseline could potentially be used when assessing treatment response to determine if the subject is an early or delayed responder. We were not able to identify other measures that could be used to predict a response in our analysis. Additional studies are therefore needed to determine if anatomic measures such as the absence of cystoid spaces, reduced central foveal thickness, time taken to achieve dryness, and presence of fibrosis at baseline [30] could also be used as predictors of treatment success. The relatively small numbers of subjects included in the subgroups may make it difficult to identify factors that might predict a response. However, Hariprasad et al. [16] also failed to identify any other factors apart from baseline BCVA that were predictive of response, and in contrast to this, our study uses data that are more closely related to real life. Larger studies are therefore needed to determine if morphological factors are able to predict a response or if there is no correlation with response.

Limitations of our analysis include its retrospective nature and our reliance on published data for inclusion in this investigation of predictors of response. Due to the complexity of the analysis and the smaller population size involved, we also did not explore the reasons why a smaller proportion of early gainers were not able to maintain their initial gains out to month 12. Despite these limita- 
tions, we believe our study provides useful information on early versus delayed responders to ranibizumab treatment in patients with nAMD that clinicians could find useful for decision making when faced with a scenario of a patient with only a modest gain in VA following the initial loading dose. Our findings should provide evidence for clinicians to delay the decision to switch from an individualized regimen of ranibizumab as long as the patient is gaining or holding the visual gains, regardless of whether there has been an early gain or not.

In conclusion, our retrospective analysis, conducted in over 1,600 subjects with nAMD across four randomized clinical trials, identified two groups of subjects who differ in the length of time needed to respond to ranibizumab with a gain of at least 15 letters. In those with a delayed response, continued ranibizumab treatment will result in VA improvements and by 12 months, this group will have achieved similar gains to the early gainers. As around 15\% of subjects might be expected to only achieve these gains between month 3 and month 12, defining treatment success after three initiation doses may be too early and we would recommend treatment is given for longer in some subjects to allow those with a delayed response to benefit from treatment and achieve almost the same level of response at 12 months as the early gainers. While we were able to show baseline VA can predict early or delayed response, further analyses are required to identify other factors that might contribute towards the response to ranibizumab treatment.

\section{Acknowledgments}

The authors thank Dr. Karen O'Leary and Dr. Elaine O'Prey from Novartis Ireland for editorial assistance.

\section{Disclosure Statement}

Dr. Richard Gale: consultancy for Allergan, Abbott, Bayer, Lux-Bio, Novartis, Santen; Prof. Jean-Francois Korobelnik: consultancy for Alcon, Allergan, Bayer, Carl Zeiss Meditec, Novartis, Roche, Thea; Prof. Yit Yang: honoraria and travel support from Alcon, Allergan, Bayer, Novartis, Pfizer, Thrombogenics, Heidelberg UK; Prof. Tien Y Wong: consultancy for Allergan, Abbott, Bayer, Novartis, Roche, and Pfizer.

\section{References}

1 Wong WL, Su X, Li X, Cheung CM, Klein R, Cheng CY, Wong TY: Global prevalence of age-related macular degeneration and disease burden projection for 2020 and 2040: a systematic review and meta-analysis. Lancet Glob Health 2014;2:e106-e116.

2 Smith W, Assink J, Klein R, Mitchell P, Klaver CC, Klein BE, Hofman A, Jensen S, Wang JJ, de Jong PT: Risk factors for age-related macular degeneration: pooled findings from three continents. Ophthalmology 2001;108:697704.

3 Kawasaki R, Yasuda M, Song SJ, Chen SJ, Jonas JB, Wang JJ, Mitchell P, Wong TY: The prevalence of age-related macular degeneration in Asians: a systematic review and metaanalysis. Ophthalmology 2010;117:921-927.

4 Lim LS, Mitchell P, Seddon JM, Holz FG, Wong TY: Age-related macular degeneration. Lancet 2012;379:1728-1738.

5 Rosenfeld PJ, Brown DM, Heier JS, Boyer DS, Kaiser PK, Chung CY, Kim RY: Ranibizumab for neovascular age-related macular degeneration. N Engl J Med 2006;355:1419-1431.

6 Brown DM, Michels M, Kaiser PK, Heier JS, Sy JP, Ianchulev T: Ranibizumab versus verteporfin photodynamic therapy for neovascular age-related macular degeneration: two-year results of the ANCHOR study. Ophthalmology 2009; 116:57-65.e5.
7 Busbee BG, Ho AC, Brown DM, Heier JS, Suner IJ, Li Z, Rubio RG, Lai P: Twelve-month efficacy and safety of $0.5 \mathrm{mg}$ or $2.0 \mathrm{mg}$ ranibizumab in patients with subfoveal neovascular age-related macular degeneration. Ophthalmology 2013;120:1046-1056.

8 Martin DF, Maguire MG, Fine SL, Ying GS, Jaffe GJ, Grunwald JE, Toth C, Redford M, Ferris FL 3rd: Ranibizumab and bevacizumab for treatment of neovascular age-related macular degeneration: two-year results. Ophthalmology 2012;119:1388-1398.

9 Martin DF, Maguire MG, Ying GS, Grunwald JE, Fine SL, Jaffe GJ: Ranibizumab and bevacizumab for neovascular age-related macular degeneration. N Engl J Med 2011;364:18971908.

10 Ho AC, Busbee BG, Regillo CD, Wieland MR, Van Everen SA, Li Z, Rubio RG, Lai P: Twenty-four-month efficacy and safety of $0.5 \mathrm{mg}$ or $2.0 \mathrm{mg}$ ranibizumab in patients with subfoveal neovascular age-related macular degeneration. Ophthalmology 2014;121:2181-2192.

11 Novartis: Lucentis (ranibizumab) summary of product characteristics 2012.

12 Wolf A, Kampik A: Efficacy of treatment with ranibizumab in patients with wet age-related macular degeneration in routine clinical care: data from the COMPASS health services research. Graefes Arch Clin Exp Ophthalmol 2014;252:647-655.
13 Droege KM, Caramoy A, Kersten A, Luberichs-Fauser J, Zilkens K, Muller D, Kirchhof B, Fauser S: Patient preference of ranibizum$\mathrm{ab}$ treatment regimen for neovascular age-related macular degeneration - monthly injections versus pro re nata. Graefes Arch Clin Exp Ophthalmol 2014;252:31-34.

14 Cazet-Supervielle A, Gozlan J, Cabasson S, Boissonnot M, Manic H, Leveziel N: Intravitreal ranibizumab in daily clinical practice for age-related macular degeneration: treatment of exudative age-related macular degeneration in real life. Ophthalmologica 2015;234: 26-32.

15 Amoaku WM, Chakravarthy U, Gale R, Gavin M, Ghanchi F, Gibson J, Harding S, Johnston RL, Kelly S, Lotery A, Mahmood S, Menon G, Sivaprasad S, Talks J, Tufail A, Yang Y: Defining response to anti-VEGF therapies in neovascular AMD. Eye 2015;29: 721-731.

16 Hariprasad SM, Morse LS, Shapiro H, Wong P, Tuomi L: Fixed monthly versus less frequent ranibizumab dosing and predictors of visual response in exudative age-related macular degeneration. J Ophthalmol 2012;2012: 690641.
Early and Delayed Response to Ranibizumab in Neovascular AMD
Ophthalmologica 2016;236:193-200 DOI: $10.1159 / 000451065$ 
17 Regillo CD, Brown DM, Abraham P, Yue H, Ianchulev T, Schneider S, Shams N: Randomized, double-masked, sham-controlled trial of ranibizumab for neovascular age-related macular degeneration: PIER Study year 1 . Am J Ophthalmol 2008;145:239-248.

18 Boyer DS, Heier JS, Brown DM, Francom SF, Ianchulev T, Rubio RG: A phase IIIb study to evaluate the safety of ranibizumab in subjects with neovascular age-related macular degeneration. Ophthalmology 2009;116:17311739.

19 Stoller GL KG, Dreyer RF, Shapiro H, Tuomi LL: Patterns of early and delayed visual response to ranibizumab treatment for neovascular age-related macular degeneration. JAMA Ophthalmol 2016;134:545-553.

20 Rezaei KA (ed.): Global Trends in Retina Survey. Chicago, American Society of Retina Specialists, 2015.

21 Gillies MC, Walton RJ, Arnold JJ, McAllister IL, Simpson JM, Hunyor AP, Guymer R, Essex RW, Morlet N, Barthelmes D: Comparison of outcomes from a phase 3 study of agerelated macular degeneration with a matched, observational cohort. Ophthalmology 2014; 121:676-681.
22 Writing Committee for the UK Age-Related Macular Degeneration EMR Users Group: The neovascular age-related macular degeneration database: multicenter study of 92976 ranibizumab injections: report 1: visual acuity. Ophthalmology 2014;121:1092-1101.

23 Ying GS, Huang J, Maguire MG, Jaffe GJ, Grunwald JE, Toth C, Daniel E, Klein M, Pieramici D, Wells J, Martin DF: Baseline predictors for one-year visual outcomes with ranibizumab or bevacizumab for neovascular age-related macular degeneration. Ophthalmology 2013;120:122-129.

24 Schmidt-Erfurth U, Waldstein SM, Deak GG, Kundi M, Simader C: Pigment epithelial detachment followed by retinal cystoid degeneration leads to vision loss in treatment of neovascular age-related macular degeneration. Ophthalmology 2015;122:822-832.

25 Waldstein SM, Philip AM, Leitner R, Simader C, Langs G, Gerendas BS, Schmidt-Erfurth U: Correlation of 3-dimensionally quantified intraretinal and subretinal fluid with visual acuity in neovascular age-related macular degeneration. JAMA Ophthalmol 2016;134:182190.
26 Zinkernagel MS, Wolf S, Ebneter A: Fluctuations in pigment epithelial detachment and retinal fluid using a bimonthly treatment regimen with aflibercept for neovascular age-related macular degeneration. Ophthalmologica 2016;235:42-48

27 Keane PA, Heussen FM, Ouyang Y, Mokwa N, Walsh AC, Tufail A, Sadda SR, Patel PJ: Assessment of differential pharmacodynamic effects using optical coherence tomography in neovascular age-related macular degeneration. Invest Ophthalmol Vis Sci 2012;53: 1152-1161.

28 Keane PA, Patel PJ, Ouyang Y, Chen FK, Ikeji F, Walsh AC, Tufail A, Sadda SR: Effects of retinal morphology on contrast sensitivity and reading ability in neovascular age-related macular degeneration. Invest Ophthalmol Vis Sci 2010;51:5431-5437.

29 Schlottmann P, Shapiro H, Tuomi L: Early vs delayed 20/40 vision achievers with ranibizumab treatment in the 24 month HARBOR study. Poster presented at EURETINA 2014.

30 Bloch SB, Lund-Andersen H, Sander B, Larsen M: Subfoveal fibrosis in eyes with neovascular age-related macular degeneration treated with intravitreal ranibizumab. Am J Ophthalmol 2013;156:116-124.e1. 